\title{
Estimation of earthquake source parameters in the Kachchh seismic zone, Gujarat, India, using three component S-wave spectra
}

\author{
Durgada Nagamani* and Prantik Mandal \\ CSIR-National Geophysical Research Institute, Hyderabad 500 00\%, India. \\ ${ }^{*}$ Corresponding author. e-mail: durgadanagamani@gmail.com
}

MS received 30 August 2016; revised 23 February 2017; accepted 25 February 2017; published online 25 July 2017

Earthquake source parameters and crustal $Q_{0}$ values for the 138 selected local events of $\left(\mathrm{M}_{\mathrm{w}}: 2.5-4.4\right)$ the 2001 Bhuj earthquake sequence have been computed through inversion modelling of S-waves from three-component broadband seismometer data. SEISAN software has been used to locate the identified local earthquakes, which were recorded at least three or more stations of the Kachchh seismological network. Three component spectra of S-wave are being inverted by using the Levenberg-Marquardt non-linear inversion technique, wherein the inversion scheme is formulated based on $\omega^{2}$ source model. SAC Software (seismic analysis code) is being utilized for calculating three-component displacement and velocity spectra of S-wave. The displacement spectra are used for estimating corner frequency (in $\mathrm{Hz}$ ) and long period spectral level (in nm-s). These two parameters play a key role in estimating earthquake source parameters. The crustal $Q_{0}$ values have been computed simultaneously for each component of three-component broadband seismograph. The estimated seismic moment $\left(M_{0}\right)$ and source radius $(r)$ using S-wave spectra range from 7.03E+12 to $5.36 \mathrm{E}+15 \mathrm{~N}-\mathrm{m}$ and 178.56 to $565.21 \mathrm{~m}$, respectively. The corner frequencies for S-wave vary from 3.025 to $7.425 \mathrm{~Hz}$. We also estimated the radiated energy $\left(E_{S}\right)$ using velocity spectra, which is varying from $2.76 \mathrm{E}+06$ to $4.07 \mathrm{E}+11$ Joules. The estimated apparent stress drop and static stress drop values range from 0.01 to 2.56 and 0.53 to $36.79 \mathrm{MPa}$, respectively. Our study also reveals that estimated $Q_{0}$ values vary from 119.0 to 7229.5 , with an average $Q_{0}$ value of 701. Another important parameter, by which the earthquake rupture process can be recognized, is Zuniga parameter. It suggests that most of the Kachchh events follow the frictional overshoot model. Our estimated static stress drop values are higher than the apparent stress drop values. And the stress drop values are quite larger for intraplate earthquakes than the interplate earthquakes.

Keywords. Source parameters; Zuniga parameter; apparent stress; 3-component S-wave spectra; Levenberg-Marquardt non-linear inversion technique; crustal $Q_{0}$ values.

\section{Introduction}

Earthquakes have been occurring in the Kachchh region of Gujarat (Rajendran and Rajendran 2001).
Two catastrophic intraplate earthquakes have occurred in the Kachchh region, within a time span of 182 yrs. One of them was great Allah Bund earthquake of $1819\left(\mathrm{M}_{\mathrm{w}}=7.8\right)$, occurred

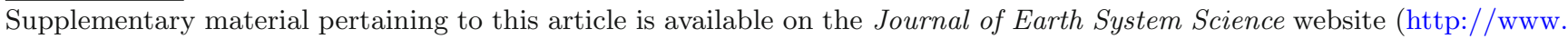
ias.ac.in/Journals/Journal_of_Earth_System_Science). 
about $100 \mathrm{~km} \mathrm{NW}$ of the 2001 Bhuj earthquake epicentre (Rajendran and Rajendran 2001). However, lack of availability of instrumental data, the estimation of source parameters is not well defined exactly. On 26th January 2001, the deadliest intraplate earthquake ever to strike in India occurred on a south dipping reverse fault in the Kachchh region of Gujarat state, which is situated in the northwestern part of India. Moment magnitude of this earthquake was reported to be $\mathrm{M}_{\mathrm{w}}=7.7$ and the focal depth in the Kachchh rift zone was reported to be $23 \mathrm{~km}$ (Mandal et al. 2004a, b; USGS 2001). Around 20,000 people were killed by this earthquake. The intensity of this earthquake was reported to be $\mathrm{X}+$ on MM scale (Rastogi et al. 2001). In 1956, another moderate earthquake $\left(\mathrm{M}_{\mathrm{w}}=6.0\right)$ had occurred in a region near Anjar, which is located south of the epicentre of the 2001 Bhuj earthquake (Chung and Gao 1995). The main motivation of the estimation of source parameters in the Kachchh region is the aftershock sequence of the 2001 Bhuj main shock, which is continuing until today with the occurrences of $\mathrm{M}_{\mathrm{w}} \geq 4.0$ earthquakes (Mandal 2007). The Kachchh in India and New Madrid in USA, only two intraplate regions have experienced large earthquakes of moment magnitude $\mathrm{M}_{\mathrm{w}} \geq 7.7$. But the estimated stress drop value ranges from 100 to 140 bars for (1811-1812) New Madrid region (Johnston and Schweig 1996), which have less stress drop values compared to 2001 Bhuj earthquake stress drop value, which is around 200 bars.

Some people have estimated stress drop values using aftershock sequence of the 2001 Bhuj main shock. Negishi et al. (2001) obtained a static stress drop ranging from 12.6 to $24.6 \mathrm{MPa}$, for an equivalent source radius ranging from 20 to $25 \mathrm{~km}$. Singh et al. (2004) suggest that a frictional sliding model with an average dynamic stress drop of about 12 $\mathrm{MPa}$ and the ratio of rupture to shear wave velocity of 0.7 could satisfactorily explain the source complexity observed for the 2001 Bhuj main shock. While Bodin and Horton (2004) estimated a static stress drop of $16.0 \pm 2 \mathrm{MPa}$ and the total rupture area was about $1300 \mathrm{~km}^{2}$. Saha et al. (2012) obtained stress drop and seismic moments ranging from 0.01 to $20 \mathrm{MPa}$ and $1.12 \times 10^{12}$ to $4 \times 10^{16} \mathrm{~N}-\mathrm{m}$, respectively. Kumar et al. (2001) estimated stress drop varying from 0.1 to $14.4 \mathrm{MPa}$, for an equivalent source radius ranging from 139.1-933.9 m. Our estimated stress drop values vary from 0.53 to 36.79 $\mathrm{MPa}$. Interplate earthquakes tend to have lower static stress drops than intraplate earthquakes
(Kanamori and Anderson 1975), but this stress drop is high even among intraplate events. The high-stress drop indicates that the near-field strong ground motions from this earthquake may have been particularly strong. According to Mandal and Johnston (2006), the stress drop values for higher magnitude events (above $10^{14.5} \mathrm{~N}-\mathrm{m}$ for Bhuj aftershocks) are scattering in nature whereas they exhibit more systematic nature $\left(\mathrm{M}_{0}^{3} \propto \Delta \sigma\right)$ for smaller seismic moment (smaller aftershocks) values. Systematic nature $\left(\mathrm{M}_{0}^{3} \propto \Delta \sigma\right)$ for smaller seismic moment values exhibit the size dependency of stress drop. Despite the source parameter estimates for other stable continental region, earthquakes globally do not show any size dependency. The large stress drops are estimated to be confined to the main rupture zone of the 2001 Bhuj earthquake and are possibly related to the large crustal stress/strain associated with a brittle, competent intrusive body of mafic nature.

\section{Geology and tectonics of the Kachchh region}

The oldest rift zone in India is the Kachchh rift zone; the Bhuj earthquake occurred in the Kachchh rift, an intraplate region of rifted Precambrian craton in northwestern India. During the break-up of Gondwana in the Jurassic, this area was affected by rifting in $\mathrm{E}-\mathrm{W}$ direction. The main characterization of the Kachchh region is Quaternary/Tertiary sediments, Deccan volcanic rocks and Jurassic sandstones resting on Archean basement (Gupta et al. 2001). The structural style of this basin is unique, and this type of structural style is not found anywhere in India. Major tectonic settings in Kachchh are a series of E-W trending uplifts along master faults with uplands surrounded by lowlands, as shown in figure 1. The rift zone is bounded by the Nagar Parker fault in the north and the Kathiawar fault in the south (Biswas 1987). In this region, the major faults oriented in the E-W trending Allah Bund Fault (ABF), Kachchh Mainland Fault (KMF), Island Belt Fault (IBF), and Katrol Hill Fault (KHF). Besides, several NESW trending small faults/lineaments are observed (Biswas 1987).

Geophysical studies such as seismic, gravity and magnetotelluric surveys reveal that an undulating basement with $2-5 \mathrm{~km}$ deep sediments, a Moho depth at 35-43 km, and a lithospheric depth at $62-77 \mathrm{~km}$ are present in the Kachchh region (Gupta et al. 2001; Reddy et al. 2001; Mandal 2011; 


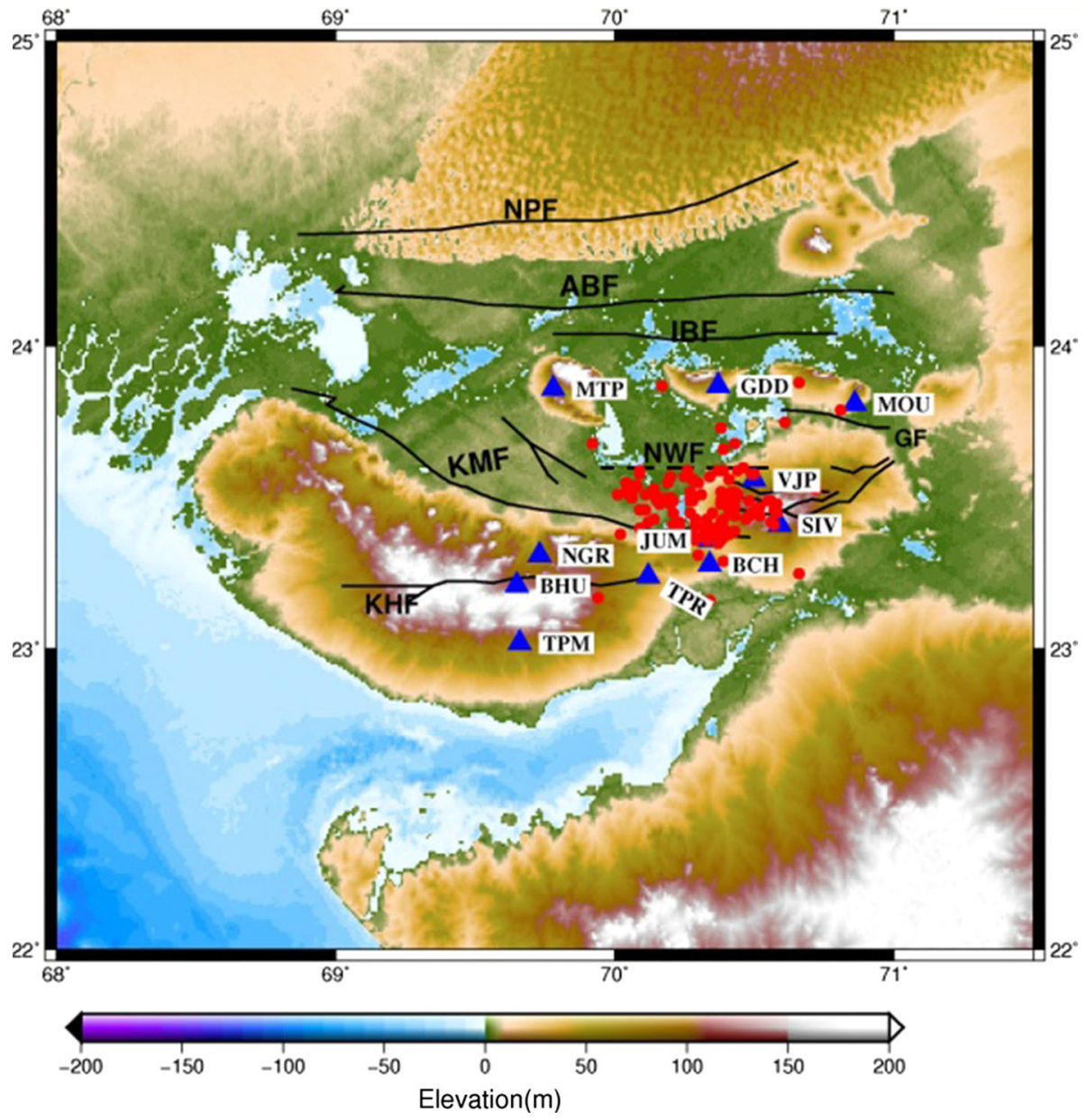

Figure 1. This figure shows location of 11 broadband seismograph stations marked by blue colour triangles and events (solid red circles). The seismological network of this region is deployed by the CSIR-NGRI. The stations are abbreviated as VJP: Vajepar, TPR: Tapar, MTP: Motapaya, GDD: Gadhada, BCH: Bhachau, NGR: Nagor, BHU: Bhuj, TPM: Tappar (Mundra), MOU: Mouvana, SIV: Shivlaka, JUM: Jumkinariya. Falut system, KMU: Kachchh Mainland Fault, KHF: Katrol hill fault, ABF: Allah bund fault, IBF: Island belt fault, NPF: Nagar Parkar fault, NWF: North Wagad fault, GF: Gedi fault.

Mandal and Pandey 2011). Overall, the tectonic setting in the region is very complex, as it consists of faults of multiple orientations and different natures (Biswas 1987).

\section{Seismic network and aftershock data}

Twelve digital broadband seismometer stations were installed by the CSIR-NGRI, Hyderabad, in the Kachchh seismically active zone. The data were recorded continuously on 24 bit REFTEK digital recorder with 100 samples per second sampling rate and a three component broadband seismograph with a natural period of $30-120 \mathrm{~s}$ for recording local, regional and teleseismic events. In our study, we selected only local events (138) of moment magnitude $\mathrm{M}_{\mathrm{w}} \geq 2.5$. Here, we used data from January
2013 to March 2014 (within $100 \mathrm{~km}$ distance from the epicentre).

\section{Methodology used for estimating source parameters}

In this work, a two-stage methodology has been used for estimating the source parameters, which is as follows:

1. Spectral analysis of S-wave using SAC (seismic analysis code) from three component broadband seismograph data.

2. Levenberg-Marquardt non-linear inversion technique has been used to invert the displacement spectra (Fletcher 1995), wherein a correction for frequency-dependent $Q\left(Q(f)=102 \mathrm{f}^{0.98}\right)$ (Mandal et al. 2004a, b) is applied. 
Table 1. $V_{p}$ and $V_{s}$ models obtained from the 1-D travel time inversion (Mandal 2007).

\begin{tabular}{lcc}
\hline $\begin{array}{l}\text { Depth to the } \\
\text { top layer }(\mathrm{km})\end{array}$ & $\begin{array}{c}V_{p} \\
(\mathrm{~km} / \mathrm{s})\end{array}$ & $\begin{array}{c}V_{s} \\
(\mathrm{~km} / \mathrm{s})\end{array}$ \\
\hline 0 & 2.92 & 0.90 \\
2 & 5.99 & 3.49 \\
5 & 5.99 & 3.77 \\
10 & 6.18 & 3.60 \\
16 & 6.07 & 3.60 \\
22 & 6.59 & 3.73 \\
29 & 7.20 & 3.99 \\
34 & 6.78 & 3.44 \\
40 & 8.20 & 4.70 \\
\hline
\end{tabular}

Local earthquakes occurring in the Kachchh region have been located using SEISAN software. First, the raw binary earthquake data files have been converted into Seisan (.sei) files by using different batch files consisting of various commands of archive utility of REFTEK Inc., USA. Next, these .sei files were registered in the SEISAN software. Then, the arrival times of the clearly visible $\mathrm{P}$ and $\mathrm{S}$ waves are picked from the vertical and horizontal components of broadband seismograms respectively, using HYPO71PC program which is integrated with SEISAN software (Lee and Valdes 1985). One-dimensional crustal velocity model is used consisting of six layers varying in velocity with depth. The layers at different depths are 0.0, $2,10,16,29,40 \mathrm{~km}$, with the corresponding Pwave velocities of $2.92,5.93,6.18,6.40,6.97$ and $8.20 \mathrm{~km} / \mathrm{s}$ (Mandal 2007) shown in table 1. At least three to four stations are needed to locate an event. The location parameters are latitude, longitude, epicentre distance, focal depth, origin time and magnitude. An azimuthal gap of less than $180^{\circ}$ of the studied seismic network provides rms value of $0.04 \mathrm{~s}$ for average location. The estimated errors of hypocentral parameters are relatively accurate, latitude and longitude error of an event is $<1.2 \mathrm{~km}$, and focal depth estimates $<2.5 \mathrm{~km}$. After successfully locating the local events (location parameters are shown in supplementary table S1), the displacement and velocity spectra of S-wave from the three-component digital recordings are calculated using a SAC script. Here, displacement spectra (window length of $2.56 \mathrm{~s}$ ) are used for computing source parameters and velocity spectra (window length of $5.12 \mathrm{~s}$ ) are used for computing radiated seismic energy.

The Levenberg-Marquardt method is a generalized inversion technique used to solve the non-linear least square problems. The LevenberMarquardt algorithm is a combination of two minimization techniques, the Gauss-Newton method and gradient decent method. It is relatively good method as it facilitates the faster convergence of the solution and minimizes the error between the inverted and observed spectra. The inversion procedure is as follows.

\subsection{Inversion procedure}

Taking the attenuation factor into consideration, the spectral amplitudes at a hypocentral distance $R$ from the source can be written as:

$$
A(f, R)=\left(A_{0} / R^{-\gamma}\right) \exp \left(\pi R f / Q_{0} V_{s}\right) .
$$

Here, $Q_{0}$ is the frequency independent S-wave quality factor; $A_{0}$ is the amplitude at the source, $f$ is the frequency, $V_{s}$ is the velocity of the S-wave and $\gamma$ is the geometrical spreading.

The exponential term can be written as:

$$
\pi R f / Q_{0} V_{s}=1 / 2^{*} 2\left(\pi R f / Q_{0} V_{s}\right)=\omega t^{*} / 2
$$

where $t^{*}=R / Q_{0} V_{s}$.

Equation (1) can be linearized by taking natural logarithm on both sides of the equation and assuming $\gamma=1$ (Fletcher 1995).

$$
\ln A(f, R)=\ln A_{0}-\ln R-\omega t^{*} / 2
$$

$A_{0}$ is the source term, and it can be written as:

$$
A_{0}=\Pi_{0} / B_{4}{ }^{0.5}=\Pi_{0} /\left[1+\left(f / f_{c}\right)^{4}\right]^{0.5} .
$$

Substituting equation (2) in equation (1) and taking $t^{*}=0$

$$
\ln [A(f, R)]=\ln \left\{\Pi_{0} /\left[1+\left(f / f_{c}\right)^{4}\right]^{0.5}\right\}-\ln (R) .
$$

The $B_{4}$ term is expanded in a Taylor series as a Newton-Raphson's method for finding roots of non-linear equations (Press 1992) and yields the final equation:

$$
\begin{aligned}
\ln A(f)= & \Pi_{0}-0.5 \ln B_{4} \\
& +2 B_{4}{ }^{-1}\left(f / f_{c}\right)^{4}\left(\Delta f_{c} / f_{c}\right)
\end{aligned}
$$

' $R$ ' term is dropped because of the fact that the formula for moment is corrected from the geometrical spreading effect. Using least-squares algorithm with several iterations solves the model parameters. 
The error is minimized in least squares sense by solving

$$
D=G M \text {. }
$$

Here $G$ is the sensitivity matrix, $M$ is the model parameter matrix and $D$ is the data matrix. Therefore,

$$
\begin{aligned}
M & =\left[\ln \Pi_{0}, \Delta f_{c}\right]^{T}, \\
G & =\left[1,2 B_{4}^{-1}\left(f / f_{c}\right)^{4} / f_{c}\right],
\end{aligned}
$$

and

$$
D=\left[A(f)+0.5 \ln B_{4}\right] .
$$

Using Newton's method for quasi-linear equation,

$$
\Delta M=\left(G^{T} G\right)^{-1} G^{T} \Delta D
$$

where $\Delta M$ is the change in model parameters and $\Delta D$ is the difference between observed and predicted data. The solution is found iteratively $M_{k}=M_{0}+\Delta M_{k-1}$, where $M_{0}$ is the initial model. Because the sensitivity matrix is near to singular here.

$$
\Delta M=\left(G^{T} G+\lambda I\right)^{-1} G^{T} \Delta D .
$$

In the above equation (10), $\lambda$ is the LevenbergMarquardt adjustable damping parameter and ' $I$ ' is the identity matrix.

In this connection, the inversion starts with initially guessed values such as corner frequency, long period spectral level, $Q_{0}$ value (for Kachchh region, $Q_{0}=102$ ), epicentral distance for a particular station and damping parameter $(\lambda)$. The $\lambda$ value varies from 0.01 to 500 . The input of corner frequency and spectral level is visually identified for respective spectrum and $\lambda$ value which starts with $0.01,1,10,20,50,80,100,120,150, \ldots, 500$. The above procedure is iterated until the best fit spectra are obtained and is shown in figure 2 which consists of different stations with different magnitudes. At the best fit spectra, the value of $Q_{0}$ and model parameters is simultaneously attained. The model parameters are corner frequency $(\mathrm{Hz})$ and long period spectral level (nm-s). Figure 3 shows the misfit, and it consists of several lines incorporated by using different parameters.

The corner frequency $(\mathrm{Hz})$ and long period spectral level (nm-s) are the foremost input parameters for estimating source parameters. Here computed corner frequencies are most robust because the average value of S-wave spectra from threecomponent broadband seismograms has been taken into consideration. The entire source parameters estimation is mainly dependent on the corner frequency which is a transition zone between low and high frequencies. After obtaining the two model parameters, we have computed other source parameters like earthquake moment magnitude, seismic moment, stress drop, apparent stress, radiated energy, and source radius, using their respective empirical equations. The formulas are mentioned below:

Seismic moment $\left(M_{0}\right)=4 \pi \rho V_{s}^{3} \Pi_{0} / F R_{\theta \phi}$

(Keilis-Borok 1959)

Source radius $(r)=\left(2.34 * V_{s}\right) /\left(2 \pi f_{c}\right)$

(Brune 1970)

Stress drop $(\Delta \sigma)=M_{0} *\left(f_{c} / 0.49 \beta\right)^{3}$

(Madariaga 1976)

where ' $V_{s}$ ' and ' $\rho$ ' are the $\mathrm{S}$-wave velocity in $\mathrm{m} / \mathrm{s}$ and rock density in $\mathrm{kg} / \mathrm{m}^{3}$ at the source respectively. ' $\Pi_{0}$ ' and ' $f_{c}$ ' represent the long-period spectral level (in nm-s) and corner frequency (in $\mathrm{Hz}$ ) respectively. ' $R$ ' is the hypocentral distance in $\mathrm{m}$, while ' $F$ ' represents the free surface amplification factor, which is assumed to be 2 for the Kachchh region. The radiation factor $\left(R_{\theta \phi}\right)$ is considered to be 0.55 for the Kachchh region (Singh et al. 2004; Mandal and Johnston 2006). The estimated $M_{0}, r$, and $\Delta \sigma$ are in $\mathrm{N}-\mathrm{m}, \mathrm{m}, \mathrm{MPa}$, respectively using the above empirical formulae. The moment magnitude is estimated using equation (14).

$$
M_{w}=(2 / 3) \log _{10}\left(M_{0}\right)-6.06
$$

(Hanks and Kanamori 1979)

\subsection{Radiated seismic energy}

S-wave energy $\left(E_{S}\right)$ associated with each earthquake in the frequency range of $0.2-25 \mathrm{~Hz}$ has been computed using equation (15) (Singh and Ordaz 1994). Here 1-D P-velocity and S-velocity structure of the Kachchh region has been used for computing radiated seismic energy (Mandal 2007). 1-D velocity model is shown in table 1 .

Radiated seismic energy

$$
\begin{aligned}
& E_{S}=\frac{4 \pi R^{2}\left[\frac{G^{2}(R)}{R^{2}}\right] \beta}{F_{s}^{2}} \\
& \times\left[2 \int_{0}^{\infty}\left[V_{N}^{2}(f)+V_{E}^{2}(f)+V_{Z}^{2}(f)\right] e^{\frac{2 \pi f R}{\beta Q(f)}} d f\right]
\end{aligned}
$$



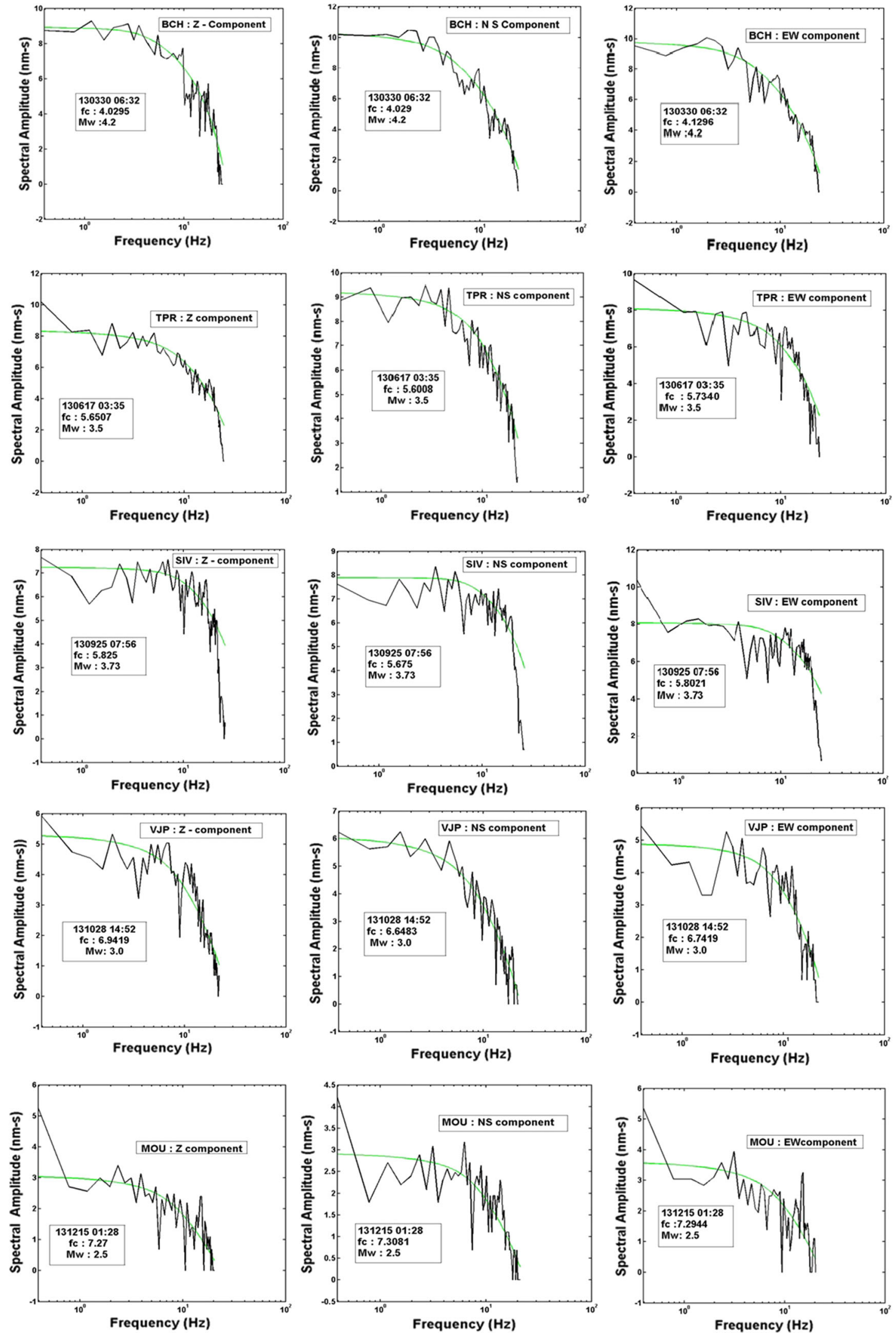

Figure 2. Some of best fit spectra for different stations with different magnitudes. The figures are plotted between frequency in $\mathrm{Hz}$ on $\mathrm{x}$-axis and log spectral amplitude in nm-s on $\mathrm{y}$-axis. The estimated S-wave spectra (black colour lines) and green colour line indicate the best fit curve. The date of occurrence, origin time, corner frequency and moment magnitude are shown in their respective plots. 

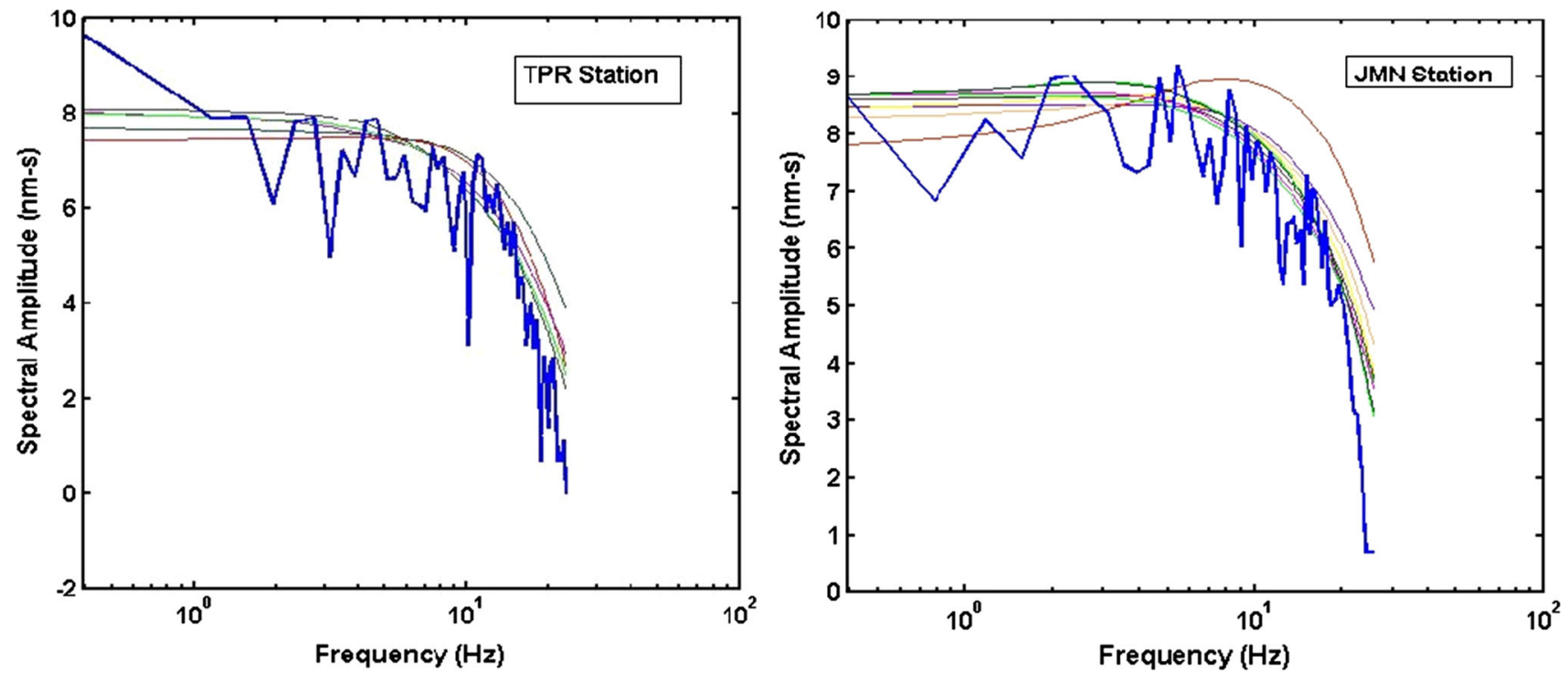

Figure 3. The figure consists of misfit spectra with several lines. These several lines incorporated by using different parameters such as input value of corner frequency, damping factor and long period spectral level.

Here ' $\beta$ ' is the shear-wave velocity which has been taken according to table 1 , ' $\rho$ ' is the density, ' $f$ ' is the corner frequency, $R$ is the hypocentral distance, $Q(f)$ is the quality factor for Kachchh region which is considered as 102 (Mandal et al. 2004a, b), $V_{N}, V_{E}, V_{Z}$ are the velocity spectra of three components (N-S, E-W and vertical), ' $F_{s}$ ' represents the free surface amplification factor which is assumed to be 2 for the Kachchh region and $G(R)$ is the geometrical spreading term, which can be written as:

$$
\begin{aligned}
& G(R)=\left\{R \text { for } R \leq R_{0}\right\} \\
& G(R)=\left\{\sqrt{ } R R_{0} \text { for } R>R_{0}\right\}
\end{aligned}
$$

where $R_{0}$ is $100 \mathrm{~km}$. S-wave velocity spectra have been used for computing radiated seismic energy, the range of frequency spectra is between 0.2 and $25 \mathrm{~Hz}$.

\subsection{Apparent stress}

Apparent stress is defined as the multiplication of average stress ' $\sigma$ ' released during the faulting and unknown seismic efficiency factor ' $\eta$ ', given by (Aki 1966):

$$
\text { Apparent stress }\left(\sigma_{a}\right)=\frac{\mu E_{S}}{M_{0}} .
$$

Here $M_{0}$ and $E_{S}$ are seismic moment $(\mathrm{N}-\mathrm{m})$ and radiated seismic energy (Joules), respectively, and rigidity modulus $\mu=3.3 \times 10^{10} \mathrm{~N} / \mathrm{m}^{2}$.

\subsection{Zuniga parameter}

Earthquake rupture process can be identified by Zuniga parameter assuming three idealized cases Orowan's model, overshoot model and partial stress drop model which are discussed here.

Let $\sigma_{1}, \sigma_{2}$ be the initial and final average stresses, and $\sigma_{f}$ be the frictional stress releases during faulting, $M_{0}$ is the seismic moment, $\mu$ is the rigidity, and $\sigma_{a}$ is the apparent stress.

The radiated seismic energy can be written as (Savage and Wood 1971):

$$
\begin{aligned}
E_{s} & =\left[\left(\sigma_{1}-\sigma_{2}\right) / 2+\left(\sigma_{2}-\sigma_{f}\right)\right]\left(M_{0} / \mu\right) \\
& =\sigma_{a}\left(M_{0} / \mu\right) .
\end{aligned}
$$

In the above equation, the average stress difference between initial $\sigma_{1}$ and final stress $\sigma_{2}$ gives the static stress drop $(\Delta \sigma)$.

Case 1: If $\sigma_{2}=\sigma_{f}$ Orowan's model (Orowan 1960), then equation (17) becomes

$$
\left[\frac{\mu E_{s}}{M_{0}}\right]=\frac{\Delta \sigma}{2}=\sigma_{a} .
$$

Case 2: If $\sigma_{2}<\sigma_{f}$ overshoot model (Savage and Wood 1971), then equation (17) becomes

$$
\left[\frac{\mu E_{s}}{M_{0}}\right]<\frac{\Delta \sigma}{2} \quad \text { and } \quad \sigma_{a}<\frac{\Delta \sigma}{2} .
$$


Case 3: If $\sigma_{2}>\sigma_{f}$ Partial stress drop-model (Brune 1970), then equation (17) becomes

$$
\left[\frac{\mu E_{s}}{M_{0}}\right]>\frac{\Delta \sigma}{2} \quad \text { and } \quad \sigma_{a}>\frac{\Delta \sigma}{2}
$$

Zuniga parameter: Zuniga proposed a model based on the above three cases in 1993 called $\varepsilon_{Z}$, by which earthquake rupture process can be identified. $\varepsilon_{Z}$ can be calculated by static stress drop and apparent stress using equation (21), which is mentioned below:

$$
\varepsilon_{Z}=\frac{\Delta \sigma}{\sigma a+\frac{\Delta \sigma}{2}} .
$$

According to Zuniga, if $\varepsilon_{Z}>1.0$ satisfies the overshoot model and if $\varepsilon_{Z}<1.0$ satisfies the partial stress drop model.

\section{Error analysis}

Error in source parameters has been calculated by estimating standard deviation and mean of the moment $\left(M_{0}\right)$, source radius $(r)$ and stress drop $(\Delta \sigma)$. The average seismic moment and source radius are determined by following equations (Archuleta et al. 1982):

$$
\left\langle M_{0}\right\rangle=\operatorname{antilog}\left[(1 / N S) \Sigma \log M_{0 i}\right]
$$

and

$$
\langle r\rangle=\left[(1 / N S) \Sigma r_{i}\right]
$$

The standard deviations $(s d)$ of the log moment are computed using the equation given below:

$$
\begin{aligned}
s d\left(\log \left\langle M_{0}\right\rangle\right)= & \{(1 / N S-1) \\
& \left.\times \Sigma\left[\log M_{0 i}-\log \left\langle M_{0 i}\right\rangle\right]^{2}\right\}^{0.5} .
\end{aligned}
$$

Multiplicative factor is also calculated using below equation:

$$
E_{m o}=\operatorname{antilog}\left\{s d\left(\log \left\langle M_{0}\right\rangle\right)\right\} .
$$

Similarly, we calculated the standard deviation of source radius and finally the standard deviation of stress drops are estimated using the equation as given below (Fletcher 1995):

$$
\sigma_{s t d}=\Delta \sigma\left\{\left(\sigma_{m} / M_{0}\right)^{2}+9\left(\sigma_{r} / r\right)^{2}\right\}^{0.5} .
$$

From the above equations, the standard deviation of the moment, stress drop, source radius, corner frequency and $E_{m o}$ have been computed for the selected 138 Bhuj aftershock sequence data. Here we used three components of (vertical and two horizontal components) broadband seismograph of Kachchh seismological network of CSIR-NGRI which are recorded on three or more stations. The maximum and minimum values of standard deviation in corner frequency, source radius and stress drop, ranges from 0.004 to $0.378 \mathrm{~Hz}, 0.46$ to 37.77 $\mathrm{m}, 0.008$ to $5.41 \mathrm{MP}$, respectively are shown in supplementary table S2.

\section{Results and discussion}

The main aim of this paper is a robust and accurate estimation of source parameters and crustal $Q_{0}$ values. Our estimated results reveal that the seismic moment $\left(M_{0}\right)$, source radius $(r)$ and stress drop values of 138 selected local events $\left(\mathrm{M}_{\mathrm{w}}: 2.5\right.$ 4.4) are varying from $7.03 \mathrm{E}+12$ to $5.36 \mathrm{E}+15 \mathrm{~N}$ $\mathrm{m}, 178.56-565.21 \mathrm{~m}$, and $0.53-36.79 \mathrm{MPa}$, respectively. There are different understandings in earthquake source scaling where one group of seismologists believes in constantly scaled energy $\left(E_{R} / M_{0}\right)$ (Choy and Boatwright 1995; McGarr 1999; Ide and Beroza 2001; Perez-Campos and Beroza 2001; Ide et al. 2003; Prieto et al. 2004), while the other group advocates that radiated energy increases with $M_{0}$ (Kanamori et al. 1993; Abercrombie 1995; Mayeda and Walter 1996; Prejean and Ellsworth 2001; Richardson and Jordan 2002; Mori et al. 2003; Stork and Ito 2004; Mayeda et al. 2005). An attempt has been made in this paper to obtain stable and reliable scaling relationships of earthquake source parameter estimates for small to moderate earthquakes occurring in Kachchh, Gujarat.

Are the earthquakes self-similar over their entire size range (Abercrombie 1995; Ide and Beroza 2001)? Different nature of normalized radiated seismic energy related to large and small earthquakes (Mayeda et al. 2005) state that earthquakes are not self-similar. The scaling relationships of earthquakes with $\mathrm{M}_{\mathrm{w}} \leq 3$ have been the subject of considerable controversy over the last two decades (Morasca et al. 2005). Studies of such events have shown that a constant source dimension (of about $100 \mathrm{~m}$ ) apparently characterize these smaller magnitude earthquakes (Abercrombie 1995). Seismic moment is proportional to the source dimension cubed, corresponding to the stress drop being 


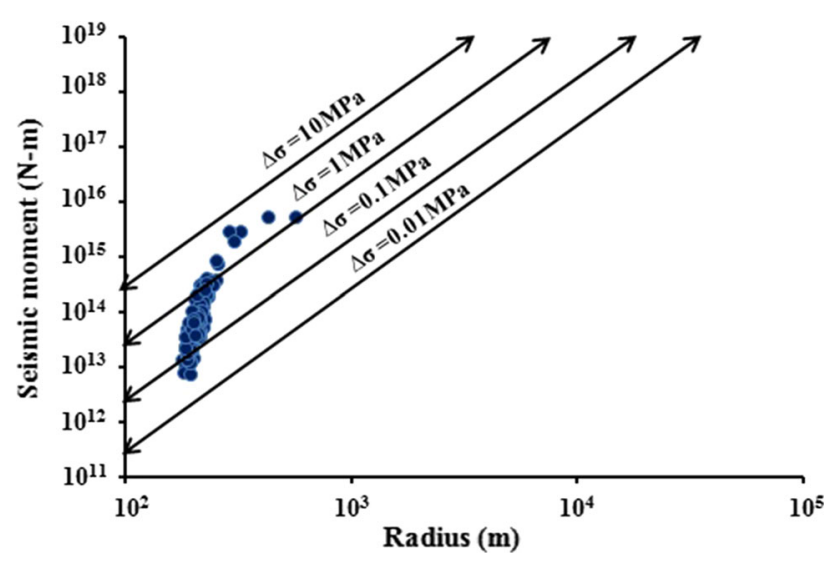

Figure 4. The seismic moment (N-m) plotted against source radius $(\mathrm{m})$ on the logarithmic scale with constant stress drop lines.

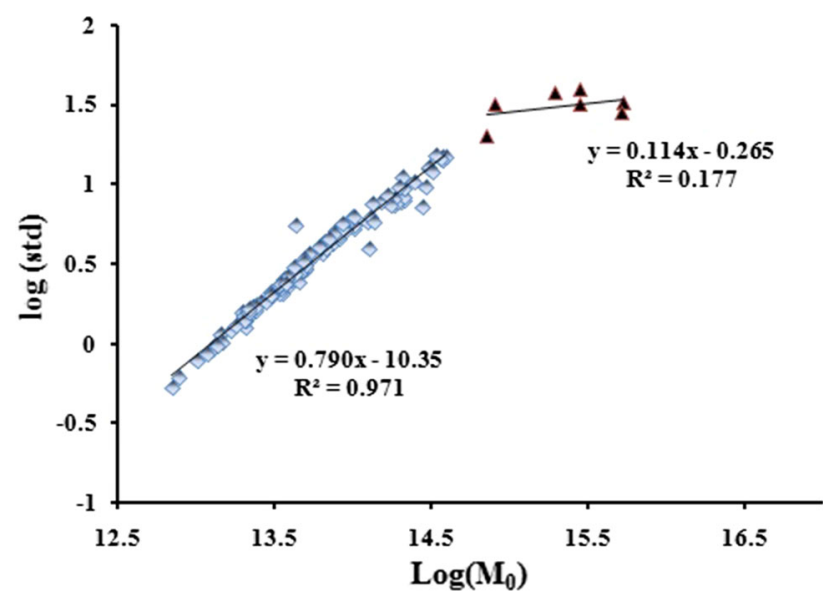

Figure 5. Plot between $\log \left(M_{0}\right)$ in N-m and $\log (\mathrm{std})$ in MPa.

independent of magnitude (Abercrombie and Rice 2005). It is inevitable to access the seismic hazard in a particular region with the knowledge of source scaling.

Figure 4 shows the seismic moment plotted against the source radius on a logarithmic scale with the constant stress drop lines. The logarithmic of the estimated seismic moment plotted against the logarithmic of static stress drop values clearly shows a break in scaling at $M_{0}=10^{14.91}$, which is shown in figure 5. From figure 4, we notice that similar break in linear scaling also identified at $M_{0}=8.128 \mathrm{E}+14$, where larger earthquakes are showing deviation from self-similar scaling and also noticed a break in source scaling between larger and smaller earthquakes at $r=251.57 \mathrm{~m}$. Corner frequency is plotted against seismic moment $\left(M_{0}\right)$ (figure 6), and it is observed that the seismic moment and corner frequencies follow non-self similarity. The cluster of lower magnitudes $\left(\mathrm{M}_{\mathrm{w}}<3\right)$ and higher magnitudes $\left(\mathrm{M}_{\mathrm{w}}>3.5\right)$ are separated

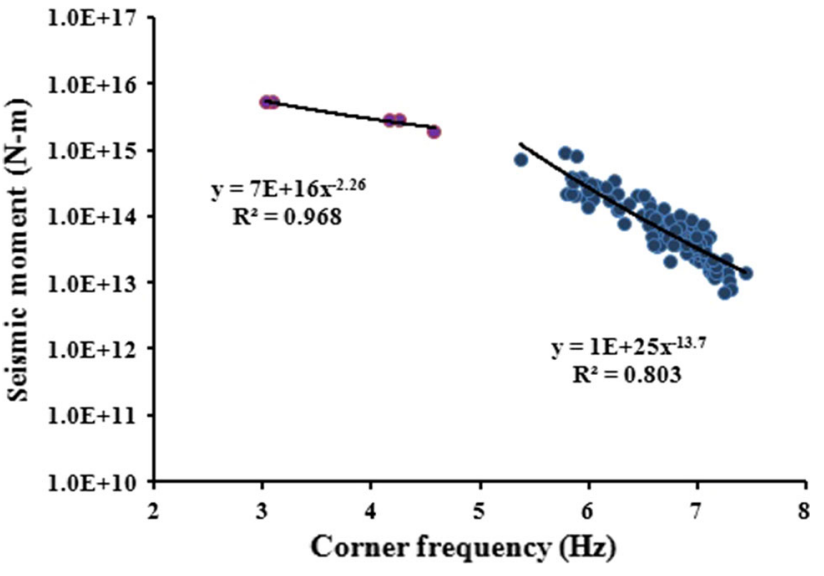

Figure 6. Shows a plot drawn between corner frequency $(\mathrm{Hz})$ and seismic moment $(\mathrm{N}-\mathrm{m})$.

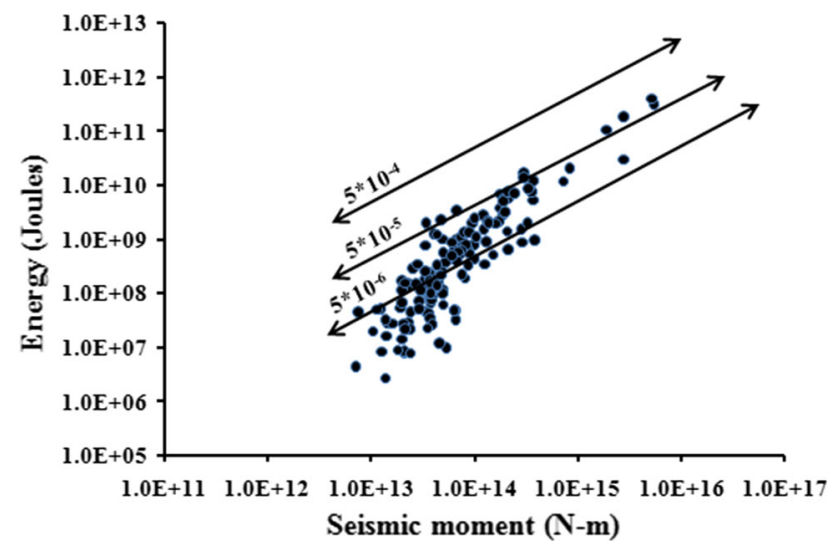

Figure 7. Showing the plot between the energy $E_{S}$ (joules) vs. seismic moment $M_{0}(\mathrm{~N}-\mathrm{m})$.

into two regions. The calculated corner frequencies are ranging from 3.025 to $7.425 \mathrm{~Hz}$. The maximum error in corner frequency is $0.378 \mathrm{~Hz}$ (table 3 ).

$E_{S}$ (in joules) and $M_{0}$ (in $\mathrm{N}-\mathrm{m}$ ) values are listed in table 3 and is plotted in figure 7 ; the black coloured lines are of constant values of $5 \times 10^{-4}$, $5 \times 10^{-5}$ and $5 \times 10^{-6}$. Smaller earthquakes are scattered and also show the systematic increase in scaled energy with increasing seismic moment. Most of the events lie between $5 \times 10^{-5}$ and $5 \times 10^{-6}$ and larger events are lying between $5 \times 10^{-4}$ and $5 \times 10^{-5}$. The ratio of $E_{S}$ and $M_{0}$ values are less for smaller earthquakes, which agrees with the global observation (Jost et al. 1998; Richardson and Jordan 2002). The average value of $E_{S} / M_{0}$ is $1.128 \mathrm{E}-05$. Figure 8 shows a variation of estimated seismic energy-to-moment ratio $\left(E_{S} / M_{0}\right)$ with moment magnitude with lines of different $\varepsilon$ values. It has been noticed that the energy may vary from a given seismic moment (figures 7 and 8). The ratio of energy to moment $E_{S} / M_{0}$ with 


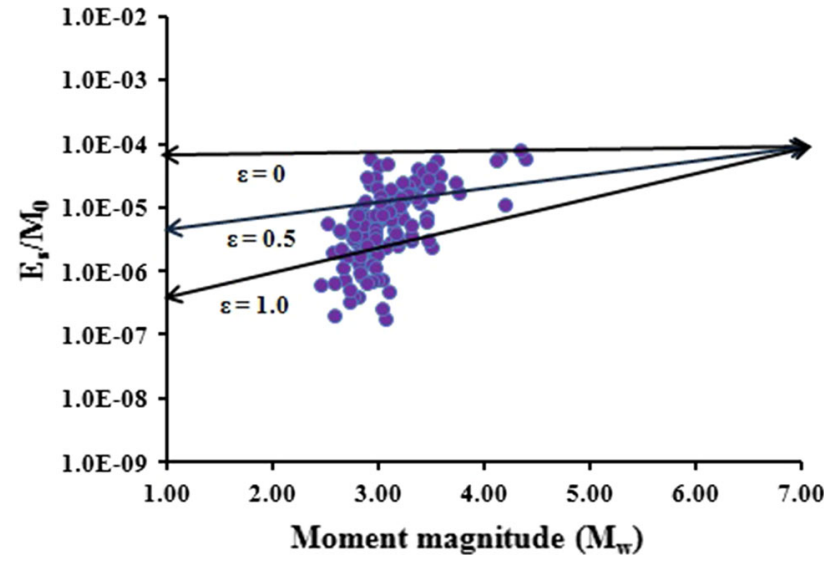

Figure 8. The plot is taking $\varepsilon=\left[E_{S} / M_{0}\right]$ on y-axis, seismic moment magnitude on $\mathrm{x}$-axis.

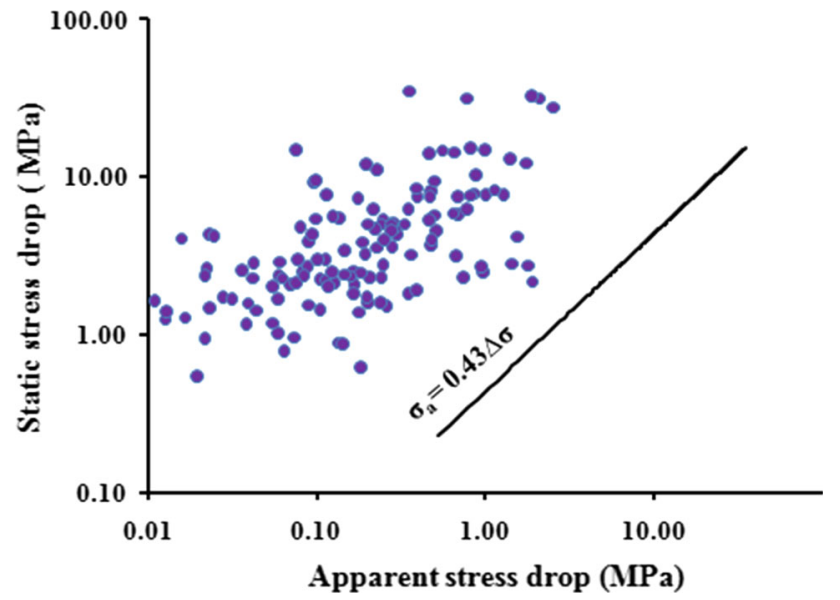

Figure 9. The graph drawn between apparent stress vs. static stress drop.

moment magnitude looks to be scattered at $\varepsilon>1$, smaller earthquakes have more scattered nature at $\mathrm{M}_{\mathrm{w}}<3.0$. Therefore, it can be revealed that smaller earthquakes radiate less radiated energy per unit fault slip than large events. From the above discussions, it can be concluded that the rupture dynamics of small and large earthquake events are different (Abercrombie and Rice 2005). Apparent stress ' $\sigma_{a}$ ', Brune model with complete stress drop $\left(\Delta \sigma_{b}\right)$ estimates and the relation $\sigma_{a}=0.43 \Delta \sigma$ are also shown in figure 9 (Singh and Ordaz 1994). Finally, we noticed that the Brune's model with complete stress drop values is higher than the apparent stress drop values and also our results satisfy the frictional overshoot model, i.e., $\left(\sigma_{a}<\Delta \sigma_{b}\right)$ suggested by Savage and Wood (1971).

The estimated apparent stress drop and static stress drop values range from 0.01 to 2.56 and 0.53 to $36.79 \mathrm{MPa}$, respectively. The variation of stress drop values with focal depth is shown in figure 10, and the values are shown in table 3. Our estimated stress drops are larger than the other

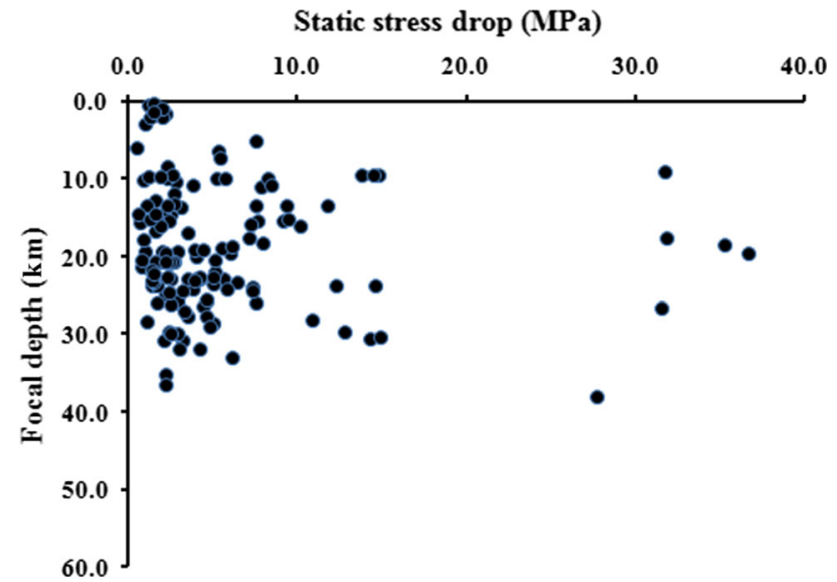

Figure 10. Represents the plot between focal depths with static stress drop values.

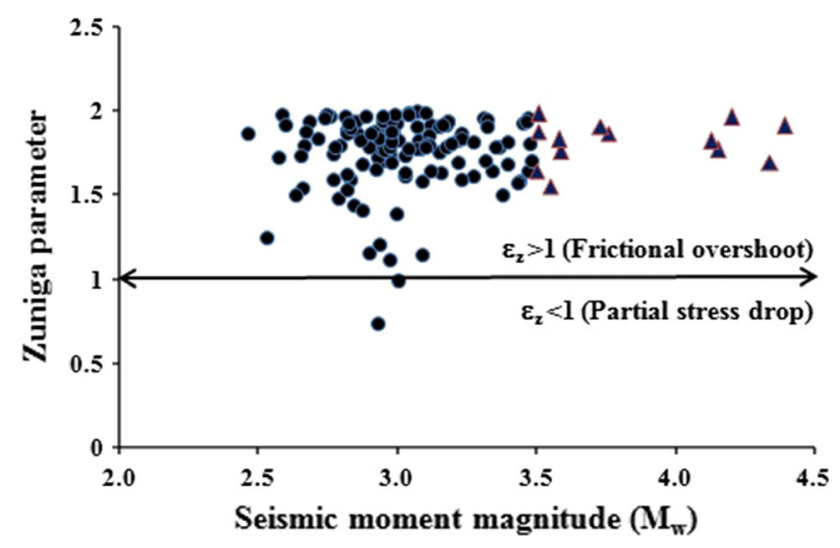

Figure 11. Represents about Zuniga parameter, the graph plotted between moment magnitude and Zuniga parameter.

earthquakes occurred in different areas. The larger stress drops obtained at which the hypocentral distance ranges from 30 to $60 \mathrm{~km}$. The reasons for obtaining higher stress drop values are the presence of crustal mafic intrusive bodies, aqueous fluids in the lower crust, and it was suggested by the earlier tomographic study of the region (Saha et al. 2012). According to Zuniga parameter $\varepsilon_{Z}$, it is observed that the studied Kachchh events follow the frictional overshoot model. All events satisfying the condition, i.e., $\varepsilon_{Z}>1$, are shown in figure 11 . The Zuniga parameter is the best identification of earthquake rupture parameter. The limits of ' $\varepsilon_{Z}$ ' are $0<\varepsilon_{Z}<2$.

An estimation of crustal $Q_{0}$ values in a seismically active region plays an important role in risk studies. In the above connection, all available frequency-dependent $Q$ for Kachchh region are discussed here. Singh et al. (2004) determined $Q$ value of Indian shield by using the spectral analysis attenuation of $\operatorname{Lg}$ waves and the estimated $Q$ value was $Q(f)=800 f^{0.42}$ with the dataset of four 
earthquakes recorded in the distance ranges from 240 to $2400 \mathrm{~km}$. Later Mandal et al. (2004a, b) computed a frequency dependent $Q\left(Q_{C}\right.$ at $\left.1 \mathrm{~Hz}\right)$ value of 102 for Kachchh region through the study of $Q_{C}$. They computed $Q$ values from Gupta et al. (2006), $Q_{C}=106 f^{1.11}, Q_{C}=148 f^{1.04}$ by Sharma et al. (2008). The low $Q$ values obtained for the Kachchh region suggest that the region is, relatively, more attenuative and heterogeneous by Mandal et al. (2004a, b), Gupta et al. (2006), and Sharma et al. (2008). Whereas according to Singh et al. (2004) and Bodin et al. (2004), the waves penetrate the deeper parts of the crust when propagating longer distances and therefore, attenuation is expected to be dependent on distance and thus obtained large $Q$ values in the deeper portion of the crust.

In the Kachchh region, the attenuation properties are deviating with the other tectonically active regions of California, Turkey and Italy. The $Q$ values in these active regions range from 100 to 300. Bodin et al. (2004) obtained the $Q$ value of 790 for Kachchh region and concluded that the seismic wave amplitudes decay much slower with distance in Kachchh region than in interplate regions (plate-boundary regions). The location with ground motion attenuation most similar to Kachchh is the New Madrid seismic zone in the central United States, with a $Q$ of 900 . Now our study shows that the estimated value of frequencyindependent $Q_{0}$ varies from 119.0 to 7229.5 with an average value of 701. Saha et al. (2012) inferred that the frequency independent average crustal $Q_{0}$ value is 840. As the stations (shown in figure 1) $\mathrm{BCH}, \mathrm{TPR}$ and VJP are located in the Kachchh basin (composed mostly with alluvium and soft sediment), the obtained values of $Q$ are low due to the thick top Quaternary sediments in the basin. The remaining stations (i.e., MTP, BHU, NAGO and TPM) which are situated in the region associated with Mesozoic uplifts, show higher $Q$ values. As we go away from the main rift zone, an increase in $Q$ values is observed (at MOU, JMN, MTP and TPM sites), which can be explained in terms of decrease in material heterogeneity in the less deformed surrounding regions (Biswas et al. 2016). Low $Q$ values at lower frequencies can be explained in terms of fluid movement in the causative fault zone and/or fluid-filled cracks in the Kachchh seismic zone (Mandal et al. 2004a, b; Padhy 2009), while high $Q$ zones (high velocity zones) could be attributed to the presence of rigid brittle less attenuative zones in the MRZ and also in the

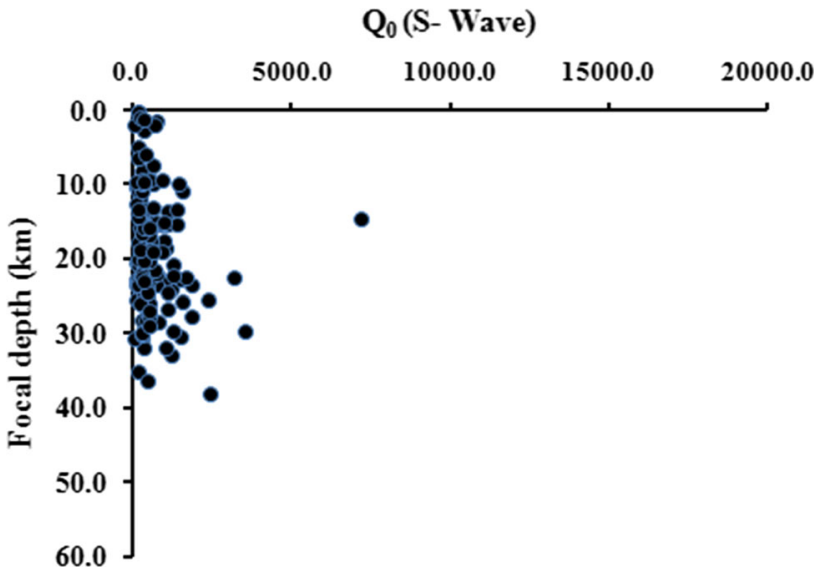

Figure 12. Represents the plot between focal depths with crustal $Q_{0}$ values.

surrounding regions (Mandal and Chadha 2008). The $Q_{0}$ factor value plotted against the focal depth and the graph is shown in figure 12 .

Later we carried out a comparative study of source parameters between 2001 Bhuj earthquake and other intraplate earthquakes that occurred in India. The estimated stress drops of 2001 Bhuj $\left(\mathrm{M}_{\mathrm{w}}\right.$ 7.7) and 1993 Latur $\left(\mathrm{M}_{\mathrm{w}} 6.2\right)$ earthquakes are reported to be 21 and $7 \mathrm{MPa}$, respectively (Baumbach et al. 1994; Antolik and Dreger 2003). The estimated static stress drop was $20 \mathrm{MPa}$ for Jabalpur earthquake of $\mathrm{M}_{\mathrm{w}} 5.7$ (Singh et al. 1999). The reservoir triggered Koyna earthquake sequence (1994-1997) suggests that the estimated stress drop ranging from 0.03 to $19 \mathrm{MPa}$ for a moment magnitude ranging from 1.5 to 4.7 (Mandal et al. 1998). We reported that our estimated stress drop value $36.79 \mathrm{MPa}$ for $\mathrm{M}_{\mathrm{w}} 4.4$ is larger than the 1993 Latur earthquake of $\mathrm{M}_{\mathrm{w}} 6.3(\sim 7 \mathrm{MPa}$, Baumbach et al. 1994). This could be attributed to the rift tectonics of the Kachchh region, but the Latur region is mainly characterized by tectonics of stable continental regions.

\section{Conclusions}

The estimated source parameters are robust because we have used three components of S-wave spectra of broadband seismograph using SAC software. Fletcher's inversion technique (1995) was used to invert the three component S-wave spectra and at best-fit spectra; simultaneously crustal $Q_{0^{-}}$ values were calculated for 138 selected aftershocks of 2001 Bhuj earthquake. The estimated apparent stress drop and static stress drop values range 
from 0.01 to 2.56 and 0.53 to $36.79 \mathrm{MPa}$, respectively. The seismic moment $\left(M_{0}\right)$, source radius $(r)$ and corner frequencies range from $7.03 \mathrm{E}+12$ to $5.36 \mathrm{E}+15 \mathrm{~N}-\mathrm{m}, 178.56$ to $565.21 \mathrm{~m}$, and 3.025 to $7.425 \mathrm{~Hz}$, respectively. We also estimated the radiated energy $\left(E_{S}\right)$ using velocity spectra, which is varying from $2.76 \mathrm{E}+06$ to $4.07 \mathrm{E}+11$ Joules.

We noticed that the seismic energy might vary from a given seismic moment. The ratio of energy to moment $E_{S} / M_{0}$ with moment magnitude looks to be scattered at $\varepsilon>1$, smaller earthquakes have more scattered nature at $\mathrm{M}_{\mathrm{w}}<3.0$, which suggests that smaller earthquakes radiate less radiated energy per unit fault slip than large events. The estimated apparent stress drop values are much smaller than the static stress drop values. We calculated Zuniga parameter $\left(\varepsilon_{Z}\right)$ (Zuniga 1993) using these two stress drops. We suggest that most of the studied Kachchh events follow the frictional overshoot model, i.e., $\varepsilon_{Z}>1$.

The computed crustal $Q_{0}$ values ranging from 119.0 to 7229.5 with an average $Q_{0}$ value of 701 for Kachchh region are nearly equal to New Madrid region $\sim 900$. The estimated stress drop, seismic moment and source radius show a clear deviation from self similarity. We notice that the stress drop values increase with increasing seismic moment. But there is a break in scaling, the larger earthquakes $\left(M_{0}>10^{14.91}\right)$ are showing one trend and smaller earthquakes $\left(M_{0}<10^{14.91}\right)$ are showing another trend.

\section{Acknowledgements}

Authors are thankful to the Director, NGRI for his support and kind permission to publish this work. This study was supported by Ministry of Earth Sciences, New Delhi and the CSIR-NGRI, Hyderabad (under GAP project).

\section{References}

Abercrombie R E 1995 Earthquake source scaling relationship from 1 to $5 \mathrm{ML}$ using seismograms recorded at 2.5 km depth; J. Geophys. Res. 100 24,015-24,036.

Abercrombie R E and Rice J R 2005 Small earthquake scaling revisited; can it constrain slip weakening?; Geophys. J. Int. $162406-424$.

Aki K 1966 Generation and propagation of G waves from the Niigata earthquake of June 16, 1964. Part 2. Estimation of earthquake moment, released energy, and stress-strain drop from the G wave spectrum; Bulk Earthq. Res. Inst., Tokyo Univ. 44 73-88.
Antolik M and Dreger D S 2003 Rupture process of the 26 January $2001 \mathrm{Mw} 7.6 \mathrm{Bhuj}$, India, earthquake from teleseismic broadband data; Bull. Seismol. Soc. Am. 93 1235-1248.

Archuleta R J, Cranswick E, Muellar C and Spudich P 1982 Source parameters of the 1980 Mammoth Lakes, California earthquake sequence; J. Geophys. Res. 87 4595-4607.

Baumbach M, Grosser H, Schmidt H G, Paulat A, Rietbrock A, Rao C V R K, Soloman Raju P, Sarkar D and Mohan I 1994 Study of the foreshocks and aftershocks of the intraplate Latur earthquake of September 30, 1993, India; Geol. Soc. India Memoir 35 33-63.

Biswas K, Kumar M and Mandal P 2016 Lapse time dependent coda-Q (Qc) in the Kachchh, rift zone, Gujarat, India; Nat. Hazards 81 1589-1610, doi: 10.1007/ s11069-016-2147-x.

Biswas S K 1987 Regional framework, structure and evolution of the western marginal basins of India; Tectonophys. $135302-327$.

Bodin P and Horton S 2004 Source parameters and tectonic implications of aftershocks of the $\mathrm{M}_{\mathrm{w}}$ 7.6 Bhuj earthquake of 26 January 2001; Bull. Seismol. Soc. Am. 94 818-827.

Bodin P, Malagnini L and Akinci A 2004 Ground motion scaling in the Kachchh Basin, India, deduced from aftershocks of the $2001 \mathrm{M}_{\mathrm{w}} 7.6$ Bhuj earthquake; Bull. Seismol. Soc. Am. 94 1658-1669.

Brune J N 1970 Tectonic stress and the spectra of seismic shear waves from earthquakes; J. Geophys. Res. $754997-$ 5009 .

Choy G L and Boatwright J L 1995 Global patterns of radiated seismic energy and apparent stress; J. Geophys. Res. 100 18,205-18,228.

Chung W Y and Gao H 1995 Source parameters of the Anjar earthquake of July 21, 1956, India, and its seismotectonic implications for the Kutch rift basin; Tectonophys. 242 281-292.

Fletcher J B 1995 Source parameters and crustal Q for four earthquakes in south Carolina; Seismol. Res. Lett. 66 $44-58$.

Gupta H K, Harinarayana T, Kousalya M, Mishra D C, Mohan I, Rao P N, Raju P S, Rastogi B K, Reddy P R and Sarkar D 2001 Bhuj earthquake of 26 January 2001; J. Geol. Soc. India 57 275-278.

Gupta S C, Kumar A, Shukla A K, Suresh G and Baidya P R 2006 Coda Q in the Kachchh Basin, western India using aftershocks of the Bhuj earthquake of January 26, 2001; Pure Appl. Geophys. 163(8) 1583-1595.

Hanks T C and Kanamori H 1979 A moment magnitude scale; J. Geophys. Res. 84(B5) 2348-2350.

Havskov J and Ottemoller L 2003 SEISAN: The Earthquake Analysis Software, manual.

Ide S and Beroza GC 2001 Does apparent stress vary with earthquake size?; Geophys. Res. Lett. 28 3349-3352.

Ide S, Beroza G C, Prejean S G and Ellsworth W L 2003 Apparent break in earthquake scaling due to path and site effects on deep borehole recordings; J. Geophys. Res. 108(B5) 2271, doi: 10.1029/2001JB001617.

Johnston A C 1994 Seismotectonic interpretations and conclusions from the stable continental regions; In: The Earthquakes of Stable Continental Regions: Assessment of Large Earthquake Potential, Electric Power and Research Institute, Palo Alto, Report TR 10261. 
Johnston A C and Schweig E S 1996 The enigma of the New Madrid earthquake of 1811-1812; Ann. Rev. Earth Planet. Sci. 24 339-384.

Jost M L, Büßelberg T, Jost O and Harjes H P 1998 Source parameters of injection-induced microearthquakes at $9 \mathrm{~km}$ depth at the KTB deep drilling site, Germany; Bull. Seismol. Soc. Am. 88 815-832.

Kanamori H K and Anderson D L 1975 Theoretical basis of some empirical relations in seismology; Bull. Seismol. Soc. Am. 65 1073-1095.

Kanamori H, Hauksson E, Hutton L K and Jones L M 1993 Determination of earthquake energy release and ML using TERRAscope; Bull. Seismol. Soc. Am. 83 330-346.

Keilis-Borok V K 1959 An estimation of the displacement in earthquake source and of source dimensions; Ann. Geofis. 12 205-214.

Kumar M, Yallanki V S, Biswas K and Mandal P 2014 Evidence for non-self-similarity in the Mw 7.72001 Bhuj earthquake sequence; Nat. Hazards, doi: 10.1007/ s11069-014-1381-3.

Lee W H K and Valdes C M 1985 HYP071PC: A personal computer version of the HYPO71 earthquake location program; U.S. Geological Survey, pp. 85-749.

Madariaga R 1976 Dynamics of an expanding circular fault; Bull. Seismol. Soc. Am. 66 639-666.

Mandal P 2007 Sediment thickness and $Q_{s}$ relations in the Kachchh rift basin, Gujarat, India using Sp converted phases; Pure Appl. Geophys. 164 135-160.

Mandal P 2011 Crustal and lithospheric thinning beneath the seismogenic Kachchh rift zone, Gujarat (India): Its implications towards the generation of the 2001 Bhuj earthquake sequence; J. Asian Earth Sci. 40 150-161.

Mandal P and Johnston A 2006 Estimation of source parameters for the aftershocks of the $2001 \mathrm{M}_{\mathrm{w}} 7.7$ Bhuj earthquake, India; Pure Appl. Geophys. 163 1537-1560.

Mandal P and Chadha R K 2008 Three-dimensional velocity imaging of the Kachchh seismic zone, Gujarat, India; Tectonophys. 452 1-16.

Mandal P and Pandey O P 2011 Seismogenesis of the lower crustal intraplate earthquake occurring in Kachchh, Gujarat, India; J. Asian Earth Sci. 42 479-491.

Mandal P, Rastogi B K and Sarma C S P 1998 Source parameters of Koyna earthquakes, India; Bull. Seismol. Soc. Am. 88(3) 833-842.

Mandal P, Srivastava J, Joshi S, Kumar S, Bhunia R and Rastogi B K 2004a Low coda-Qc in the epicentral region of the 2001 Bhuj Earthquake of $\mathrm{M}_{\mathrm{w}}$ 7.7; Pure Appl. Geophys. 161 1635-1654.

Mandal P, Rastogi B K, Satyanarayana H V S, Kousalya M, Vijayraghavan R, Satyamurthy C, Raju I P, Sarma A N $\mathrm{S}$ and Kumar N 2004b Characterization of the causative fault system for the 2001 Bhuj earthquake of $\mathrm{M}_{\mathrm{w}} 7.7$; Tectonophys. 378 105-121.

Mayeda K, Gök R, Walter W R and Hofstetter A 2005 Evidence for non-constant energy/moment scaling from codaderived source spectra; Geophys. Res. Lett. 32 L10306, doi: 10.1029/2005GL022405.

Mayeda K and Walter W R 1996 Moment, energy, stress drop, and source spectra of western United States earthquakes from regional coda envelopes; J. Geophys. Res. 101 $11,195-11,208$.
McGarr A 1999 On relating apparent stress to the stress causing earthquake fault slip; J. Geophys. Res. 104 30013003.

Morasca P, Mayeda K, Malagnini L and Walter W R 2005 Coda derived source spectra, moment magnitudes, and energy-moment scaling in the western Alps; Geophys. J. Int. $160263-275$.

Mori J, Abercrombie R E and Kanamori H 2003 Stress drops and radiated energies of aftershocks of the 1994 Northridge, California, earthquake; J. Geophys. Res. 108(B11) 2545, doi: 10.1029/2001JB000474.

Negishi H, Mori J, Singh R P and Kumar S 2001 Aftershocks and slip distribution of mainshock: A comprehensive survey of the 26 January 2001 Bhuj earthquake $\left(M_{w} 7.7\right)$ in the state of Gujarat, India; Research Report on Natural Disaster, pp. 33-35.

Orowan E 1960 Mechanism of seismic faulting; Geol. Soc. Am. Memoir 79 323-345.

Padhy S 2009 Characteristics of body-wave attenuations in the Bhuj crust; Bull. Seismol. Soc. Am. 99 33003313.

Pe'rez-Campos X and Beroza G C 2001 An apparent mechanism dependence of radiated seismic energy; J. Geophys. Res. 106 11,127-11,136.

Prejean S G and Ellsworth W L 2001 Observations of earthquake source parameters at $2 \mathrm{~km}$ depth in the Long Valley Caldera, eastern California; Bull. Seismol. Soc. Am. 91 165-177.

Press W H et al. 1992 Numerical recipes in Fortran and $C$; Academic Press, New York, 382p.

Prieto G A, Shearer P M, Vernon F L and Kilb D 2004 Earthquake source scaling and self-similarity estimation from stacking P and S spectra; J. Geophys. Res. 109 B08310, doi: 10.1029/2004JB003084.

Rajendran C P and Rajendran K 2001 Character of deformation and past seimicity associated with 1819 Kachchh earthquake, northwestern India; Bull. Seismol. Soc. Am. 91(3) 407-426.

Rastogi B K, Gupta H K, Mandal P, Satyanarayana H V S, Kousalya M, Raghavan R, Jain R, Sarma A N S, Kumar N and Satyamurty C 2001 The deadliest stable continental region earthquake occurred near Bhuj on 26 January 2001; J. Seismol. 5 609-615.

Reddy P R, Sarkar D, Sain K and Mooney W D 2001 A report on collaborative scientific study at USGS; Menlo Park, USA.

Richardson E and Jordan T H 2002 Seismicity in deep gold mines of South Africa: Implications for tectonic earthquakes; Bull. Seismol. Soc. Am. 92 1766-1782.

Saha A, Lijesh S and Mandal P 2012 Simultaneous estimation of earthquake source parameters and crustal $Q$ value from broadband data of selected aftershocks of the 2001 $\mathrm{M}_{\mathrm{w}} 7.7$ Bhuj earthquake; J. Earth Syst. Sci. 121 14211440.

Savage J C and Wood M W 1971 The relation between apparent stress and stress drop; Bull. Seismol. Soc. Am. 61 1381-1386.

Seismic Analysis Code SAC2000 2000 (http://www.iris.edu/ manuals/sac/SAC_Home_Main.html), p. 280.

Sharma B, Gupta A K, Devi K D, Kumar D, Teotia S S and Rastogi B K 2008 Attenuation of high-frequency seismic 
waves in Kachchh Region, Gujarat, India; Bull. Seismol. Soc. Am. 98(5) 2325-2340.

Singh S K and Ordaz M 1994 Seismic energy release in Mexican subduction zone; Bull. Seismol. Soc. Am. 84(5) 1533-1550.

Singh S K, Pacheco J F, Bansal B K, Perez-campos X, Dattatrayam R S and Suresh G 2004 A source study of the Bhuj, India earthquake of 26 January, $2001\left(\mathrm{M}_{\mathrm{w}}\right.$ 7.6); Bull. Seismol. Soc. Am. 94(4) 1195-1206.

Singh S K, Ordaz M, Dattatrayam R S and Gupta H K 1999 A spectral analysis of the May 21, 1997, Jabalpur, India earthquake $\left(M_{w}=5.8\right)$ and estimation of ground motion from future earthquakes in the Indian shield region; Bull. Seismol. Soc. Am. 89 1620-1630.

Stork A L and Ito H 2004 Source parameter scaling for small earthquakes observed at the western Nagano 800-m deep borehole, central Japan; Bull. Seismol. Soc. Am. 94 17811794.

USGS 2001 http://earthquake.usgs.gov/earthquakes/ eqarchives/year/2001/2001_01_26.php.

Zuniga F R 1993 Frictional overshoot and partial stress drop, which one?; Bull. Seismol. Soc. Am. 83 939-944.

Corresponding editor: N V ChalaPATHI RAO 